\title{
Biotechnological production of 1,3-propanediol from crude glycerol
}

\author{
Agnieszka Drożdżyńska, Katarzyna LeJA*, Katarzyna CZaczyK \\ Department of Biotechnology and Food Microbiology, Poznań University of Life Sciences, Poznań, Poland \\ *Corresponding author: katleja@up.poznan.pl
}

\begin{abstract}
1,3-Propanediol (1,3-PD) is one of the important products used in chemical industry, in particular for polyesters production (e.g. polyethers and polyurethanes). Using crude glycerol for producing 1,3-PD is a good solution from the economical as well as ecological point of view. Glycerol produced by cleavage of natural fats can be microbially converted to 1.3-propanediol by, among others, Citrobacter, Klebsiella, Lactobacillus, Enterobacter, and Clostridium strains. Biotechnological production of 1,3-PD from waste biomass is a promising and attractive alternative to the traditional chemical synthesis. The production of 1,3-PD by glycerol fermentation was already reported in 1881. The microbiological bioconversion pathway of glycerol to 1,3-PD has been known for long but the microorganisms taking part in this fermentation are not efficient. In addition, they are pathogenic. Consequently, natural producers of 1,3-PD are still being sought. In this review we present a historical outline of 1,3-PD production, as well as the microorganisms and their metabolic pathways that are involved in glycerol fermentation to 1,3-PD.
\end{abstract}

Key words: bioconversion, glycerol, HPLC, 1,3-propanediol

\section{Introduction}

The shortage of resources of crude oil has induced an increase in biofuels production. Biofuels are a wide range of fuels which are in some way derived from biomass. The most common biofuel in Europe is biodiesel. Biodiesel is made from vegetable oils, animal fats or recycled greases. An increase in biodiesel production generates a huge amount of waste glycerol - one part of glycerol is produced for every 10 parts of biodiesel. This fact has a negative influence on the price of biodiesel. In 2009 , the biodiesel production rose up to 10 million tons per year in UE, and 1.5 million tons in Poland (Papanikolaou et al., 2000; Kośmider et al., 2009). In the biodiesel production process, the glycerin phase is obtained as a by-product. The glycerin phase includes glycerol, methanol, mono- and diaceloglycerols, fatty acids, and soap. Approximately 200-300 tones of the glycerin phase are generated every year, causing environmental problems regarding the management of this by-product. One solution to this threat is an application of a glycerin phase or raw glycerol as a carbon source in microbial growth media used in the production of a metabolite such as 1,3PD (Kośmider et al., 2009; Kośmider et al., 2010). Moreover, crude glycerol may also be used as a raw material in citric acid, succinic acid, propionic acid, and dihydroxyacetone production (Rywińska, 2010; Kośmider et al., 2009).

1,3-PD is also known as a trimethylene glycol, 1.3-dihydroxypropane, propane-1,3-diol. Molecular formula of the compound is $\mathrm{C}_{3} \mathrm{H}_{8} \mathrm{O}_{2}$ (Fig. 1), molecular mass $76.09 \mathrm{~g}$ $\times \mathrm{mol}^{-1}$, the boiling point is $210-212^{\circ} \mathrm{C}$ and melting point is $-28^{\circ} \mathrm{C}$ (Igari et al., 2000). 1,3-PD is a typical product of glycerol fermentation (Katrlik et al., 2007). It is a valuable chemical intermediate potentially used in the manufacture of polymers (among others, polyesters, polyethers, polyurethanes), cosmetics, lubricants, medicines, and as an intermediate in the synthesis of heterocyclic compounds (Menzel et al., 1997; Biebl et al., 1999). Recently, 1,3-PD is also used as a monomer to synthesize a new type of polyester - polytrimethylene terephthalate (Biebl et al., 1999; Zeng et al., 2002; Liu et al., 2007; Zhang et al., 2007).

In the past, 1,3-PD was produced only chemically by two methods: the hydration of acrolein or the hydroformylation of ethylene. The chemical synthesis, however, has many disadvantages - it requires high pressure, high temperature and catalysts. Consequently, the costs of 1,3-PD production are very high (Igari et al., 2000). An 


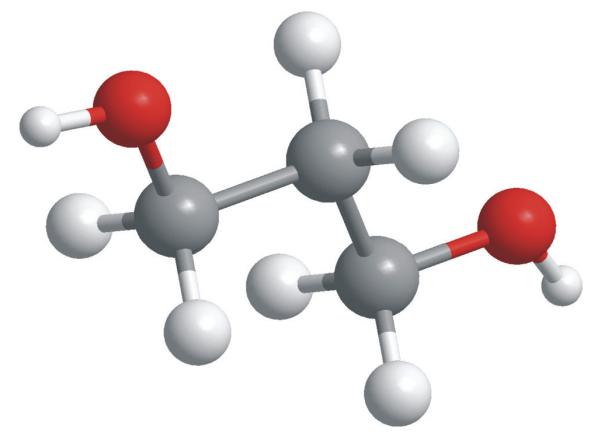

Fig. 1. A ball and stick model of the 1,3-propanediol molecule. (Werle et al., 2006)

attractive alternative for chemical synthesis is a microbial conversion of raw materials to 1,3-PD. This method is easy and does not generate toxic by-products. Nevertheless, the major limitation for industrial microbial production of 1,3-PD is the relatively high cost of the typical substrate such as glucose. The economically attractive solution to this problem might be the use of crude glycerol (without prior purification) as a fermentative substrate, (Nakumara et al., 2003; Mu et al., 2006).

Glycerol is a renewable resource found as a by-product of ethanolic fermentation of glucose (Petitdemange et al., 1995; Kośmider et al., 2009). Glycerol can be converted to 1,3-PD by many microorganisms such as Klebsiella pneumonia, Bacillus welchi, Lactobacillus ssp., Enterobacter spp., Citrobacter spp., and Clostridia spp. (Liu et al., 2007). It is fermented by a dismutation process involving two parallel pathways. In one pathway, glycerol is transformed to dihydroxyacetone by a glycerol dehydrogenase and in the other one a coenzyme $\mathrm{B}_{12}$-dependent glycerol dehydratase converts glycerol to 3-hydroxypropionaldehyde (Daniel et al., 1999; Zhang et al., 2007). Other metabolites can also be obtained from glycerol, e.g. dihydroxyacetone, succinic acid, citric acid, docosahexanoic acid, propionic acid, hydrogen, and ethanol (Daniel et al., 1999; Kośmider et al, 2009).

This review deals with the biotechnological production of 1,3-PD as a good alternative to the conventional chemical synthesis of this compound.

\section{Historical outline}

1,3-PD - one of the oldest known fermentation products - was identified in 1881 by August Freund, as a product of glycerol fermentation by Clostridium pasterianum. Next, in 1914, the Bacillus ssp. which produces this substance was described by Voisenet. In 1928, the
Microbiology School of Delft commenced analyses of the fermentation process with different Enterobacteriaceae producing 1,3-PD. This research was later continued at Ames, Iowa, in the U.S. However, the first Clostridium ssp. producing 1,3-PD were described as late as in 1983, (Nakas et al., 1983; Biebl, 1999).

In the 1990s, three technical processes for the production of 1,3-PD were developed: the first one uses acrolein, the second ethylene oxide, and in the third one glucose is used as a raw material. Nowadays, there is an increasing interest in microbial production of 1,3-PD especially from oil industry (Katrlík et al., 2007).

\section{Microorganisms}

A number of microorganisms can grow anaerobically on glycerol as the sole carbon and energy source. This group includes: Clostridiumbutyricum (Colin et al., 2000), Clostridium pasteurianum (Biebl et al., 1992), Clostridium diols, Clostridium acetobutylicum, Clostridium butylicum, Clostridium perfingens, (Hao et al., 2008), Enterobacter agglomerans (Barbirato et al., 1998), Enterobacter aerogenes (da Silva et al., 2009), Klebsiella pneumonia (Biebl et al., 1998), Klebsiella oxytoca (Homann et al., 1990), Klebsiella aerogenes, Citrobacter freundii (Malinowski, 1999), Lactobacillus reuterii, Lactobacillus buchnerii, Lactobacillus collinoides, Pelobacter carbinolicus, Rautella planticola (Saxena et al., 2009), and Bacillus welchii (da Silva et al., 2009). Unfortunately, a huge problem is that the best 1,3-PD producers are pathogenic. In Table 1 two potential industrial producers of 1,3-PD from glycerol - Clostridia and Enterobacteriaceae are compared, and Table 2 presents production of 1,3-PD from crude and pure glycerol by Clostridium butyricum, Clostridium acetobutyricum, and Klebsiella pneumoniae.

The production of 1,3-PD from glycerol is generally performed under anaerobic conditions using glycerol as the sole carbon source in the absence of other exogenous reducing equivalent acceptors (Nakamura et al., US Patent, 2000). However, such strains like Klebsiella Pneumoniae, Klebsiella oxytoca, Klebsiella aerogenes, Enterobacter agglomerans, Enterobacter aerogenes, Citrobacter freundii, Lactobacillus reuteri, Lactobacillus buchnerii, Lactobacillus collinoides, Pelobacter carbinolicus, and Rautella planticola can produce 1,3-PD in micro-aerobic fermentation (Biebl et al., 1998; Saxena et al., 2009, da Silva et al., 2009). 
Table 1. Comparison of two potential industrial producers of 1,3-PD from glycerol - Clostridium and Enterobacteriaceae (Willke and Vorlop, 2008)

\begin{tabular}{l|l}
\hline \multicolumn{1}{c|}{ Clostridium } & \multicolumn{1}{c}{ Enterobacteriaceae } \\
\hline Risk Class 1 (GRASS) & Risk Class 2 (potentially pathogenic) \\
\hline Strictly anaerobic, therefore difficult to handle & Facultative aerob, robust organisms, easy handling \\
\hline Spore forming & No sporulation \\
\hline Main by-products: acetic acid, butyric acid & Main by-products: ethanol, acetic acid \\
\hline Yield: about $0.5 \mathrm{~kg}$ PDO $/ \mathrm{kg}$ glycerol & Yield: about $0.4 \mathrm{~kg}$ PDO $/ \mathrm{kg}$ glycerol \\
\hline Max. theor. yield: $0.72 \mathrm{~mol} / \mathrm{mol}$ & Max. theor. yield: $0.72 \mathrm{~mol} / \mathrm{mol}$ \\
\hline
\end{tabular}

Table 2. Production of 1,3-PD from crude and pure glycerol by Clostridium and Klebsiella pneumoniae strains (modified, based on Choi, 2008)

\begin{tabular}{|c|c|c|c|}
\hline $\begin{array}{c}\text { Product } \\
\text { (concentration, yield) }\end{array}$ & By-products & Substrate & Strain \\
\hline $\begin{array}{c}\text { 1,3-propanediol } \\
(48 \mathrm{~g} / \mathrm{l}, \mathrm{Y}=0.66)\end{array}$ & acetate, butyrate & crude glycerol & $\begin{array}{l}\text { Clostridium butyricum } \\
\text { F2b }\end{array}$ \\
\hline $\begin{array}{c}\text { 1,3-propanediol } \\
(30.5 \mathrm{~g} / \mathrm{l}, \mathrm{Y}=0.61)\end{array}$ & acetate, butyrate & crude glycerol & $\begin{array}{c}\text { Clostridium acetobutylicum } \\
\text { DG1 (pSPD5) }\end{array}$ \\
\hline $\begin{array}{c}\text { 1,3-propanediol } \\
(86 \mathrm{~g} / \mathrm{l}, \mathrm{Y}=0.65)\end{array}$ & acetate, butyrate & pure glycerol & $\begin{array}{c}\text { Clostridium acetobutylicum } \\
\text { DG1 (pSPD5) }\end{array}$ \\
\hline $\begin{array}{c}\text { 1,3-propanediol } \\
(66.6 \mathrm{~g} / \mathrm{l}, \mathrm{Y}=0.69)\end{array}$ & butyrate & pure glycerol & $\begin{array}{c}\text { Clostridium butyricum } \\
\text { VPI3266 }\end{array}$ \\
\hline $\begin{array}{l}\text { 1,3-propanediol } \\
(48.5 \mathrm{~g} / \mathrm{l})\end{array}$ & butanediol, acetate & pure glycerol & $\begin{array}{c}\text { Klebsiella pneumoniae } \\
\text { DSM } 2026\end{array}$ \\
\hline $\begin{array}{c}\text { 1,3-propanediol } \\
(63.4 \mathrm{~g} / \mathrm{l}, \mathrm{Y}=0.69)\end{array}$ & acetate, butyrate & crude glycerol & $\begin{array}{c}\text { Clostridium butyricum } \\
\text { CNCM } 1211\end{array}$ \\
\hline $\begin{array}{c}\text { 1,3-propanediol } \\
(70.5 \mathrm{~g} / \mathrm{l}, \mathrm{Y}=0.699)\end{array}$ & $\begin{array}{c}\text { acetate, ethanol, } \\
\text { lactic acid, 2,3-butanediol }\end{array}$ & pure glycerol & $\begin{array}{c}\text { Klebsiella pneumoniae } \\
\text { DA-1HB }\end{array}$ \\
\hline $\begin{array}{l}\text { 1,3-propanediol } \\
(63.2 \mathrm{~g} / \mathrm{l}, \mathrm{Y}=0.6)\end{array}$ & not determined & crude glycerol & $\begin{array}{l}\text { Klebsiella pneumoniae } \\
\text { ACCC10082 }\end{array}$ \\
\hline
\end{tabular}

\section{Factors influencing product formation}

In the 1,3-PD fermentations, product formation depends mainly on the ability of the sources of carbon and energy as well as on hydrogen concentration. In the case of fermentation by Klebsiella pneumoniae when glycerol is a limiting factor, the formation of cell biomass is optimized and large amounts of ethanol are produced. However, if only glycerol appears in the medium (because of increasing inhibition by the products), ethanol formation ceases and the 1,3-PD yield approaches its maximum value. When the excess of glycerol increases, lactic acid, 2,3-butanediol and succinic acid can be observed, in yields respectively to about 10,7 and below $2 \%$ of the glycerol. The formation of butyrate in Clostridia is comparable to ethanol formation in Klebsiella. However, it is more dependent on the growth rate. In the case of the absence of substrate excess, rapid decrease of butyrate is observed (Biebl et al., 1998; Biebl et al., 1999).

In batch fermentation with Enterobacteriaceae the accumulation of 3-hydroxypropionaldehyde is observed. It is a toxic metabolite which inhibits the growth of bacteria and the formation of 1,3-PD (Zeng et al., 1993; Zeng et al., 1994; Barbirato et al., 1996; Biebl et al., 1998; Biebl et al., 1999).

The productivity of 1,3-PD can be improved through the application of metabolic and genetic engineering 
procedures. Basically, it may be done in three ways: (i) by introduction an additional gene coding for the enzyme that allows the formation of glycerol from sugars or intermediates of glycolysis, into a bacterial strain that already produces 1,3-PD from glycerol; (ii) by introduction of genes coding for enzymes which allow the conversion of glycerol into 1,3-PD into an organism which could not do it naturally; or (iii) by introduction of both types of genes into an organism which could not produce glycerol, intermediates of glycolysis and 1,3-PD (Laffend et al., 1997; Nevoigt and Stahn, 1997; Saxena et al., 2008; Celińska, 2010).

There are a few scientists who use these strategies today. Among them is Nakamura who together with his colleagues reported that 1,3-PD can be produced by recombinant microorganisms from various sugars; e.g. from glucose, fructose, lactose, sucrose, maltose, and mannose (Nakamura et al. 2000). The other one, Chotani, constructed a strain of $E$. coli containing the genes from Saccharomyces and K. pneumoniaefor glycerol and 1,3-PD production, respectively (Chotani et al. 2000). In addition, Saxena and co-workers obtained a genetically modified $E$. coli strain which can produce 1,3-PD from glucose (Saxena et al., 2008).

In a report of DuPont and Genecor International Inc., a metabolically engineered $E$. colicould produce up to $135 \mathrm{~g} / \mathrm{l}$ of $1,3-\mathrm{PD}$ with a yield of $0.6 \mathrm{~mol} 1,3-\mathrm{PD} / \mathrm{mol}$ glucose (Nakamura et al., 2003; Saxena et al., 2008).

\section{Metabolic pathways}

Klebsiella spp., Citrobacter spp., Clostridium spp., and Enterobacter spp. metabolize glycerol both oxidatively and reductively. In the oxidative pathway the conversion of glycerol to dihydroxyacetone is catalyzed by the $\mathrm{NAD}^{+}$-dependent glycerol dehydrogenase. The next step is phosphorylation of the latter product, which is catalyzed by the glycolytic enzyme dihydroxyacetone kinase. Then, the phosphorylated product is subjected to glycolysis (Daniel et al., 1995; Luers et al., 1997; Macis et al., 1998; Zhu et al., 2002; da Silva et al., 2009). In the reducing pathway, glycerol is converted to 3-hydroxypropionaldehyde in reactions catalyzed by coenzyme $\mathrm{B}_{12}$-dependent glycerol dehydratase and related diol dehydratases. Next, 3-hydroxypropionaldehyde is reduced to $1,3-\mathrm{PD}$ and the $\mathrm{NAD}^{+}$is regenerated by the $\mathrm{NADH}^{+} \mathrm{H}^{+}$dependent enzyme 1,3-propanediol dehydrogenase (1,3propanediol-oxydoreductase) (Ahrens et al.,1998; da Sil- va et al., 2009; Forage and Foster, 1982; Knietsch et al., 2003; Németh et al., 2003).

Figure 2 shows the biochemical pathways for glycerol fermentation to 1,3-PD as the end product. During this process, glycerol is dehydrogenated to dihydroxyacetone which then can be converted (after phosphorylation) to pyruvate. This step is catalyzed by the enzyme glycerol $\mathrm{NAD}^{+}$dehydrogenase. Glycerol dehydrogenase is a coenzyme $\mathrm{B}_{12}$-dependent enzyme composed of three polypeptides. It catalyzes the free radical mediated conversion of glycerol to 3-hydroxypropionaldehyde (Nakumara et al., 2003). The reductive glycerol conversion consists in a vitamin $\mathrm{B}_{12}$-mediated dehydration to 3-hydroxypropionaldehyde and a reduction of the aldehyde to 1,3-PD (Biebl et al., 1999; Katrlík et al., 2007). Unfortunately, in all of the wild 1,3-PD producers, there is a low molar yield of 1,3-PD to glycerol conversion - 0.51 to 0.65 or 0.54 to 0.64 when $20 \mathrm{~g} / 1$ or $70 \mathrm{~g} / 1$ of glycerol is added to the culture media respectively (Zhang et al., 2007).

Pyruvate formed during glycerol conversion may be utilized in different ways. For example, in the Enterobacteriaceae it is cleaved to acetyl-CoA. It can also be condensed to $\alpha$-acetolactate and finally transformed to acetoin and 2,3-butanediol. As a result of glycerol fermentation by Enterobacteriaceae, the accumulation of two main products, 1,3-PD and acetate, is observed. Depending on the culture conditions, the secondary products, lactate, formate, succinate and ethanol, are generated in variable amounts (Dabrock et al., 1992; Biebl et al., 1999). In case of 1,3-PD production by Lactobacillus brevis acetic acid, ethanol, and lactic acid are also obtained as by-products (Willke and Vorlop, 2008). The 1,3-PD is the main product together with butyric acid and acetic acid as by-products when fermentation is conducted by Clostridium butyricum. Cl. butyricum is one of the best "natural producers" of 1.3-PD. Also a variety of metabolic end products, such as 1,3-PD, n-butanol, ethanol, acetic acid, butyric acid, and lactic acid, are obtained as a result of glycerol fermentation by $C$. pasteurianum (Homann, 1990; Barbirato et al., 1998; Biebl, 2001; da Silva et al., 2009) (Fig. 3). The synthesis of 1,3-PD by this microorganism is not a vitamin B12-dependent process, which is clearly an economical advantage for an industrial application (Saint-Amans et al., 1994; Gonzàlez-Pajuelo et al., 2006). 


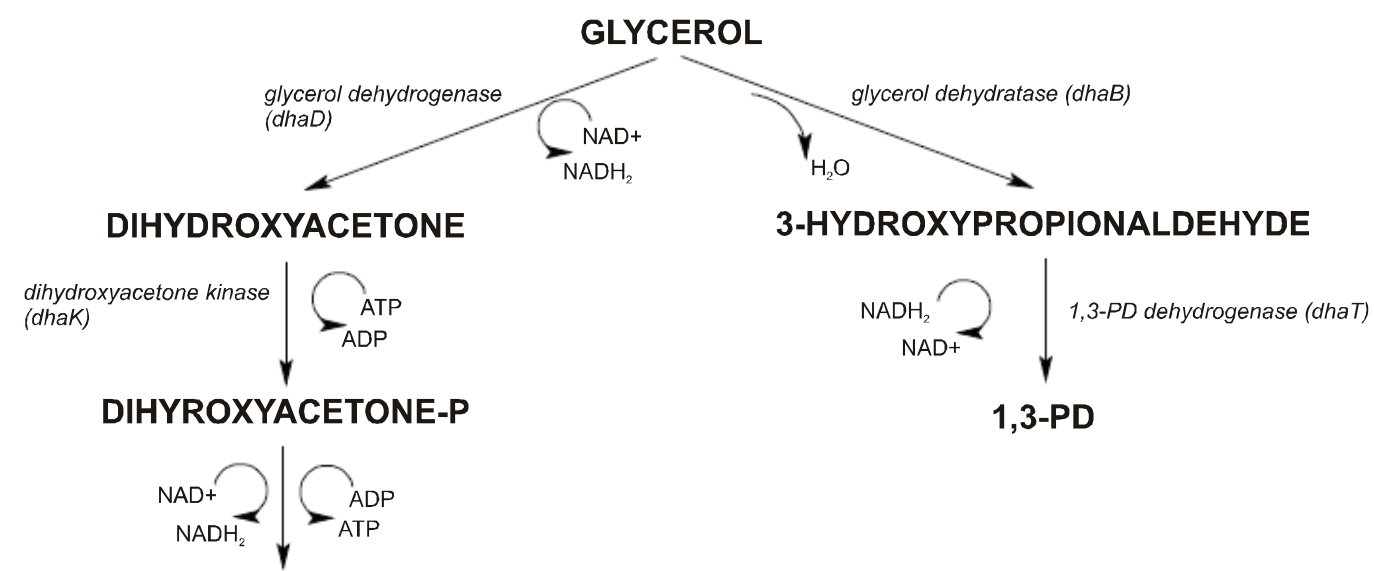

PHOSPHOENOLPYRUVATE

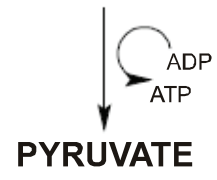

Fig. 2. Biochemical pathways of glycerol fermentation (Biebl et al., 1999)

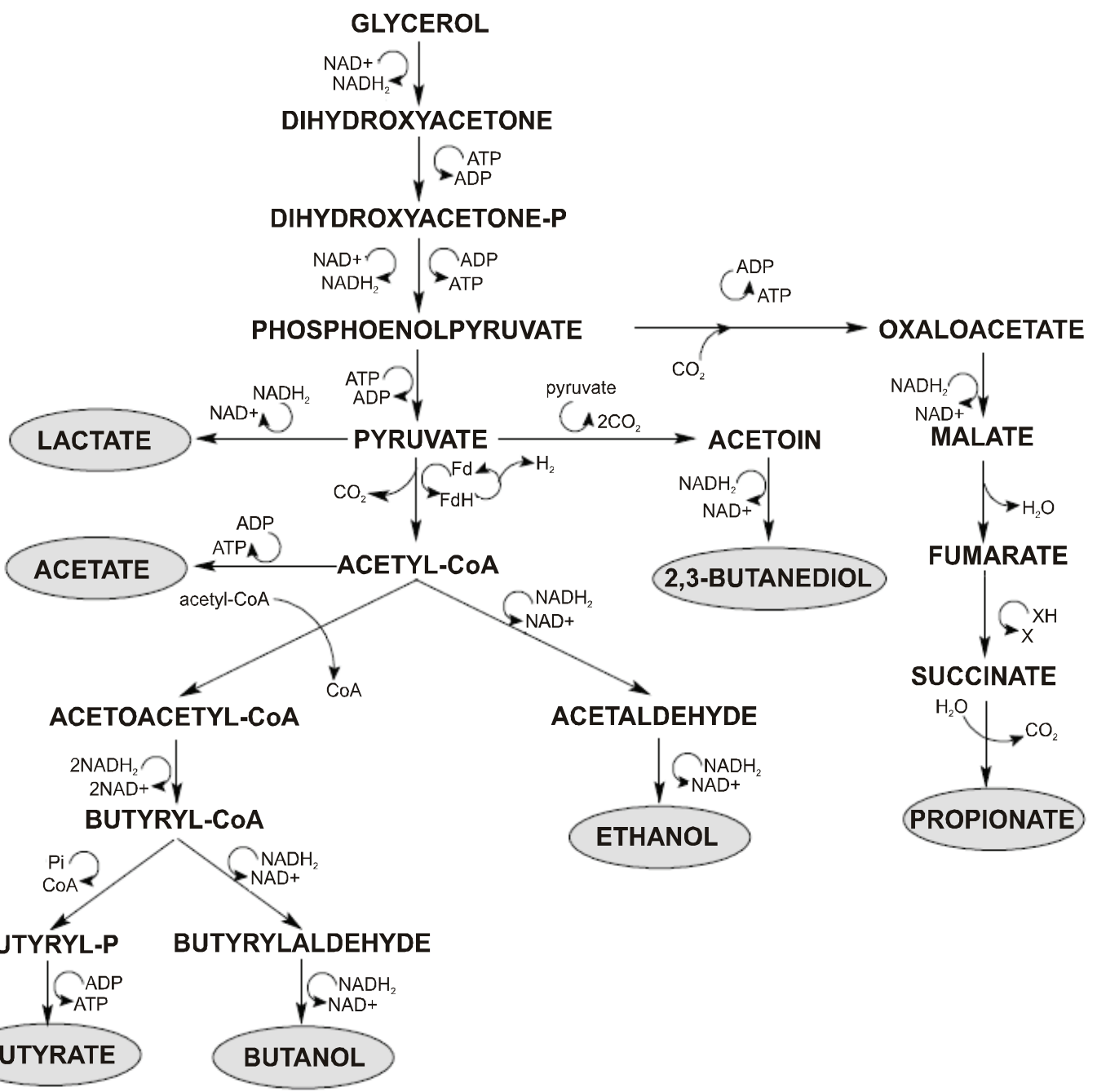

Fig. 3. The end-products of glycerol fermentation by different microorganisms (da Silva et al., 2009) 


\section{Problems in microbial production of 1,3-PD}

The main reason for the low yield and productivity of glycerol fermentation to of 1,3-PD is that bioprocesses are carried out at physiological temperature, atmospheric pressure and mostly in batch operation mode (Zeng et al., 2002). A process approach can have a significant effect on volumetric production rates by increasing cell density in the bioreactor and by developing a continuous process. This is mostly achieved by the optimization of the process conditions along with the application of fedbatch and continuous operation mode with cell recycling or with immobilized cells (Saxena et al., 2009; Zeng et al., 2002). The rather low product concentration, compared with chemical processes resulting in high downstream processing costs, is the other limitation of bioprocesses. This is mainly caused by product-mediated inhibition of cell growth and biosynthesis. Physiological improvements in cell growth and product formation have only a limited impact. Chemical or directed mutagenesis may provide a better chances to overcome this problem. Unfortunately, the molecular mechanisms of product-mediated inhibition are not well understood (Zeng et al., 2002).

To make 1,3-PD production economical, by-products or waste streams generated during the production of the biofuels are used. In this context, glycerol-rich streams, which occur during biodiesel production, may have a potential use. (Saxena et al., 2009). Utilization of raw glycerol in the fermentation process offers a remarkable advantage against pure glycerol. However, it is still hard to escape the general conclusion that utilizing raw glycerol as the starting feedstock for microbial production is difficult. It is due to such reasons like high crude glycerol prices as have been the case over the past two years and very low value of crude glycerol derived as a by-product from biofuels production processes (Yazdani et al., 2007; Rehman et al., 2008; Saxena et al., 2009).

\section{Optimization of 1,3-PD production by Klebsiella pneumoniae bioconversion process}

As it was mentioned before, in addition to the product-mediated inhibition, also by-products (i.e. ethanol, 2,3-butanediol, acetic acid) can limit the yield of 1,3-PD production. 3-hydroxypropionaldehyde seems to be the strongest inhibitor. This compound is normally an intermediate that does not accumulate within the cell. Howe- ver, under conditions of high glycerol excess, it may be excreted into the medium (Zeng et al., 2002).

The main ways to optimize the microbial production of 1,3-PD from glycerol are: preventing undesired byproduct formation in order to achieve high product yield; increasing the productivity of the bioreactor; and increasing the tolerance for 1,3-PD in order to maximize the final product concentration (Zeng et al., 2002).

In the case of Klebsiella pneumoniae, in continuous culture, under conditions of high glycerol excess and significant product inhibition, other by-products (inter alia 2,3-butanediol and lactic acid) appear in the medium diminishing the propanediol yield (Zeng et al., 1994; Menzel et al., 1997; Zeng et al., 2002). The pH lower than 6.5 is not favorable to $1,3-\mathrm{PD}$ production because low $\mathrm{pH}$ stimulates the production of 2,3-butanediol (Biebl et al., 1998; Zeng et al., 2002; Celińska et al., 2009). It was also observed that hydrogen gas released from pyruvate cleavage to acetyl coenzyme A increases the efficacy of propanediol formation (Zeng et al., 1993; Zeng, 1996; Zeng et al., 2002). K. pneumoniae simultaneously use two enzymes pyruvate dehydrogenase and pyruvate formate lyase for anaerobic cleavage of pyruvate in the glycerol fermentation. Pyruvate dehydrogenase generates $\mathrm{NADH}_{2}$ from pyruvate cleavage (instead of forming formate with pyruvate formate lyase) leading to an increased yield of 1,3-PD. However, if acetyl-CoA is channeled into the tricarboxylic acid cycle, the yield of 1,3-PD is much higher (Zeng et al., 2002). Klebsiella pneumoniae is a good 1,3-PD producer, however the use of this microorganism is limited because of its pathogenic properties.

\section{Future prospects}

The demand for energy sources is increasing together with the increasing population of the world. The overall biodiesel production in the EU increased twice during the last six years. Moreover, biodiesel production in the EU is forecast to increase to $12 \mathrm{Mt}$ in 2011. By 2016, the global biodiesel market is estimated to reach 37 billion gallons (Sims, 2007; Behr et al., 2008; Saxena et al., 2009).

Bioconversion of crude glycerol obtained in biodiesel production seems to be highly recommended. First of all, it provides substrates for the production of biodegradable polymers and this way directly benefit the environ- 
ment. In addition, wide application of biodegradable polymers would promote the use of biodiesel and reduce petroleum dependency (Saxena et al., 2009). An interesting example of application of the product of glycerol fermentation is a polyethylene terephthalate (PTT) production. PTT polymer is a member of a family of polymers based on fiber-grade 1,3-PD. It is a linear crystallizable polymer with a melting temperature of about $228^{\circ} \mathrm{C}$ and a glass transition temperature of about $50^{\circ} \mathrm{C}$. Production of such polymers with the use of biological systems has a number of advantages over classical chemical technologies e.g. greenhouse gas emission in the manufacture of bio-1,3-PD has been demonstrated to be about $40 \%$ less than for petrochemical 1,3-PD. Moreover, recycling of PTT is made much easier owing to the absence of heavy metals in the product, compared to PET and Nylon (Kurian, 2005).

\section{Conclusion}

Today there is considerable industrial interest in microbial-based 1,3-PD production, as it appears to be competitive with traditional technologies utilized to obtain this compound. 1,3-PD is a very useful bulk chemical, with a variety of applications. It is used in the manufacture of polymers, cosmetics, food, lubricants, and medicines. 1,3-PD can be produced by chemical synthesis or by biotechnological routes from waste biomass, for example from crude glycerol obtained in the production of biodiesel. The biotechnological method seems to be an attractive alternative to the traditional chemical production. However, the main microorganisms which can be used in 1,3-PD production are pathogenic. Our task for the future is to find effective non-pathogenic microorganisms capable of producing 1,3-PD from glycerol.

\section{Acknowledgments}

The paper was prepared within the framework of project no.01.01.02-00-074/09 co-funded by the European Union from the European Regional Development Fund within the framework of the Innovative Economy Operational Programme 2007-2013.

\section{References}

Ahrens K., Menzel K., Zeng A.P., Deckwer W.-D. (1998) Kinetic, dynamic, and pathway studies of glycerol metabolism by Klebsiella pneumoniae in anaerobic continuous culture: III. Enzymes and fluxes of glycerol dissimilation and 1,3-propanediol formation. Biotechnol. Bioeng. 59: 544-552.
BarbiratoF., GrivelJ.P., SoucailleP., Bories A. (1996) 3-hydroxypropionaldehyde, an inhibitory metabolite of glycerol fermentation to 1,3-propanediol by enterobacterial species. Appl. Environ. Microbiol. 62: 1448-1451.

Barbirato F., Himmi E.H., Conte T., Bories A. (1998) 1,3-propanediol production by fermentation: An interesting way to valorize glycerin from the ester and ethanol industries. Ind. Crops Prod. 7: 281-289.

Behr A., Eilting J., Irawadi K., Leschinski J., Lindner F. (2008) Improved utilization of renewable resources: new important derivatives of glycerol. Green Chem. 10: 13-30.

Biebl H., Marten S., Hippe H., Deckwer W.-D. (1992) Glycerol conversion to 1,3-propanediol by newly isolated clostridia. Appl. Microbiol. Biotechnol. 36: 592-597.

Biebl H., Zeng A.-P., Menzel K., Deckwer W.-D. (1998) Fermentation of glycerol to 1,3-propanediol and 2,3-butanediol by Klebsiella pneumonia. Appl. Microbiol. Biotechnol. 50: 24-29.

Biebl H., Menzel K., Zeng A.-P., Deckwer W.-D. (1999) Microbial production of 1,3-propanediol. Appl. Microbiol. Biotechnol. 52: 289-297.

Biebl H. (2001) Fermentation of glycerol by Clostridium pasteurianum - batch and continuous culture studies. J. Ind. Microbiol. Biotech. 27: 18-26.

Celińska E., Grajek W. (2009) Biotechnological production of 2,3-butanediol - current state and prospects. Biotechnol. Adv. 27: 715-725.

Celinska E. (2010) Debottlenecking the 1,3-propanediol pathwaybymetabolic engineering. Biotechnol Adv. 28: 519-530.

Choi W.J. (2008) Glycerol-based biorefinery for fuels and chemicals. Recent Patents Biotechnol. 2(3): 173-180.

Chotani G., Dogde T., Hsu A., Jumar M., la Duca R., Trimbur D. et al. (2000) The commercial production of chemicals using pathway engineering. Biochim. Biophys. Acta 1543: 434-455.

Colin T., Bories A., Moulin G. (2000) Inhibition of Clostridium butyricum by 1,3-propanediol and diols during glycerol fermentation. Appl. Microbiol. Biotechnol. 54: 201-205.

da Silva G.P., Mack M., Contiero J. (2009) Glycerol: A promising and abundant carbon source for industrial microbiology. Biotechnol. Adv. 27: 30-39.

Dabrock B., Bahl H., Gottschalk G. (1992) Parameters affecting solvent production by Clostridium pasteurianum. Appl. Environ. Microbiol. 58: 1233-1239.

Daniel R., Stuertz K., Gottschalk G. (1995) Biochemical and molecular characterization of the oxidative branch of glycerol utilization by Citrobacter freundii. J. Bacteriol. 177: 4392-4401.

Daniel R., Thomas A.B., Gottschalk G. (1999) Biochemistry of coenzyme $B_{12}$-dependent glycerol and diol dehydratases and organization of the encoding genes. FEMS Microbiol. Rev. 22: 553-566.

Forage R.G., Foster A.M. (1982) Glycerol fermentation in Klebsiella pneumoniae: functions of the coenzyme B12-dependent glycerol and diol dehydratases. J. Bacteriol. 149: 413-419. 
Gonzàlez-Pajuelo M., Meynial-Salles I., Mendes F., Soucaille P., Vasconcelos I. (2006) Microbial conversion of glycerol to 1,3-propanediol: physiological comparison of a natural producer, Clostridium butyricum VPI 3266, and an engineered strain, Clostridium acetobutylicum DG1(pSPD5). Appl. Environ. Microbiol. 72(1): 96-101.

Hao J., Wei W., Jiesheng T., Jilun L., Dehua L. (2008) Decrease of 3-hydroxypriopionaldehyde accumulation in 1,3propanediol production by over-expressing dhaT gebe in Klebsiella pneumonia TUAC01. J. Ind. Microbiol. Biotechnol. 35: 735-741.

Homann T., Tag C., Biebl H., Deckwer W.-D., Schink B. (1990) Fermentation of glycerol to 1,3-propanediol by Klebsiella and Citrobacter strains. Appl. Microbiol. Biotechnol. 33: 121-126.

Igari S., Mori S., Takikawa Y. (2000) Effects of molecular structure of aliphatic diols and polyalkylene glycol as lubricants on the wear of aluminum. Wear 244: 180-184.

Katrlík J., Vostiar I., Sefcovicová J., Tkác J., Mastihuba V., Valach M., Stefuca V., Gemeiner P. (2007) A novel microbial biosensor based on cells of Gluconobacter oxydans for the selective determination of 1,3-propanediol in the presence of glycerol and its application to bioprocess monitoring. Anal. Bioanal. Chem. 388(1): 287-295.

Knietsch A., Bowien S., Whited G., Gottschalk G., Daniel R. (2003) Identification and characterization of coenzyme $B_{12}$-dependent glycerol dehydratase-and diol dehydrataseencoding genes from metagenomic DNA libraries derived from enrichment cultures. Appl. Env. Microbiol. 69: 3048-3060.

Kośmider A., Czaczyk K. (2009) The prospects of use of glycerol in biotechnological processes. Progr. Microbiol. 48(4): 277-287 (in Polish).

Kośmider A., Drożdżyńska A., Czaczyk K. (2009) The possible use of waste raw materials in propionic fermentation. Food Sci. Technol. Quality 6(67): 47-58 (in Polish).

Kośmider A., Drożdżyńska A., Blaszka K., Leja K., Czaczyk K. (2010) Propionic acid production by Propionibacterium freudenreichii ssp. shermanii using industrial wastes: crude glycerol and whey lactose. Pol. J. Environ. Stud. 19(6): 1249-1253.

Kurian J.V. (2005) A new polymer platform for the futuresorona from corn derived 1,3-propanediol. J. Polym. Environm. 13(2): 159-167.

Liu H.-J., Zhang D.-J., Xu Y.H., Mu Y., Sun Y.-Q., Xiu Z.-L. (2007) Microbial production of 1,3-propanediol from glycerol by Klebsiella pneumoniae under micro-aerobic conditions up to a pilot scale. Biot. Lett. 29: 1281-1285.

Luers F., Seyfried M., Daniel R., Gottschalk G. (1997) Glycerol conversion to 1,3-propanediol by Clostridium pasteurianum: cloning and expression of the gene encoding 1,3propanediol dehydrogenase. FEMS Microbiol. Lett. 154: 337-345.

Macis L., Daniel R., Gottschalk G. (1998) Properties and sequence of the coenzyme $B_{12}$-dependent glycerol dehydra- tase of Clostridium pasteurianum. FEMS Microbiol. Lett. 164: 21-28.

Malinowski J. (1999) Evaluation of liquid extraction potentials for downstream separation of 1,3-propanediol. Biot. Tech. 13: 127-130.

Menzel K., Zeng A.-P., Deckwer W.-D. (1997) High concentration and productivity of 1,3-propanediol from continuous fermentation of glycerol by Klebsiella pneumonia. Enzyme Microb. Technol. 20: 82-86.

Mu Y., Teng H., Zhang D.-J., Wang W., Xiu Z.-L. (2006) Microbial production of 1,3-propanediol by Klebsiella pneumoniae using crude glycerol from biodiesel preparations. Biotechnol. Lett. 28: 1755-1759.

Nakamura C.E., Gatenby A.A., Hsu A.K., Reau R.D., Haynie S.L., Diaz-Torres M. et al. (2000) Method for the production of 1,3-propanediol of recombinant microorganism. United States Patent No. 6, 013, 494.

Nakumura C.E., Whited G. (2003) Metabolic engineering for the microbial production of 1,3-propanediol. Curr. Opin. Biotechnol. 14: 454-459.

Nakas J.P., Schaedle M., Parkinson C.M., Coonley C.E., Tanenbaum S.W. (1983) System development for linked-fermentation products of solvents from algal biomass. Appl. Environ. Microbiol. 46: 1017-1023.

Németh A., Kupcsulik B., Sevella B. (2003) 1,3-Propanediol oxidoreductase production with Klebsiella pneumoniae DSM2026. World J. Microbiol. Biotechnol. 19: 659-663.

Nevoigt E., Stahn U. (1997) Osmoregulation and glycerol metabolism in the yeast Saccharomyces cerevisiae. FEMS Microbiol. Rev. 21: 231-241.

Papanikolaou S., Ruiz-Sanchez P., Pariset B., Blanchard F., Fick M. (2000) High production of 1,3-propanediol from industrial glycerol by a newly isolated Clostridium butyricum strain. J. Biotech. 77: 191-208.

Petitdemange E., Dürr C., Abbad Andaloussi S., Raval G. (1995) Fermentation of raw glycerol to 1,3-propanediol by new strains of Clostridium butyricum. J. Ind. Microbiol. 1(15): 498-502.

Rehman A., Matsumur A.M., Nomura N., Sato S. (2008) Growth and 1,3-propanediol production on pre-treated sunflower oil bio-diesel raw glycerol using a strict anaerobe Clostridium butyricum. Curr. Res. Bacteriol. 1(1): 7-16.

Rywińska A. (2010) Application of crude glycerol in citric acid production by Yarrowia Lipolytica Wratislavia AWG 7. Biotechnology 9(2): 13-22.

Saint-Amans S., Perlot P., Goma G., Soucaille P. (1994) High production of 1,3-propanediol from glycerol by Clostridium butyricum VPI 3266 in a simply controlled fed-batch system. Biotech. Lett. 16: 831-836.

Saxena R.K., Pinki A., Saurabh S., Jasmine I. (2009) Microbial production of 1,3-propanediol: recent developments and emerging opportunities. Biotechnol. Adv. 27: 805-913.

Sims B. (2007) Biodiesel: a good perspective. Biodiesel Magazine, http://www. Biodieselmagazine.com/article.jsp? article_id=1961. 
Werle P., Morawietz M., Lundmark S., Sörensen K., Karvinen E., Lehtonen J. (2006) Alcohols, Polyhydric. [in:] Ullmann's Encyclopedia of Industrial Chemistry, Wiley-VCH, Weinheim.

Willke T., Vorlop K. (2008) Biotransformation of glycerol into 1,3-propanediol. Eur. J. Lipid Sci. Technol. 110: 831-840.

Yazdani S.S., Gonzales R. (2007) Anaerobic fermentation of glycerol: a path to economic viability for the biofuels industry. Curr. Opin. Biotechnol. 18: 213-218.

Zeng A.P. (1996) Pathway and kinetic analysis of 1,3-propanediol production from glycerol fermentation by Clostridium butyricum. Bioproc. Eng. 14: 169-175.

Zeng A.P., Biebl H., Schlieker H., Deckwer W.D. (1993) Pathway analysis of glycerol fermentation by Klebsiella pneumoniae: regulation of reducing equivalent balance and product inhibition. Enzyme Microb. Technol. 15: 771-779.

Zeng A.P., Ross A., Biebl H., Tag C., Guènzel B., Deckwer W.D.
(1994) Multiple product inhibition and growth modeling of Clostridium butyricum and Klebsiella pneumoniae in glycerol fermentation. Biotechnol. Bioeng. 44: 902-911.

Zeng A.P., Biebl H. (2002) Bulk chemicals from biotechnology: the case of 1,3-propanediol production and the new trends. Adv. Biochem. Eng./Biotechnol. 74: 239-259.

Zhang G.L., Maa B.B., Xua X.L., Chun L., Wang L. (2007) Fast conversion of glycerol to 1,3-propanediol by a new strain of Klebsiella pneumonia. Bioch. Eng. J. 37: 256-260.

Zhu M.M., Lawman P.D., Cameron D.C. (2002) Improving 1.3propanediol production from glycerol in a metabolically engineered Escherichia coli by reducing accumulation of sn-glycerol-3-phosphate. Biotechnol. Prog. 18: 694-699. 